\title{
An experimentally induced Chlamydia suis infection in pigs results in severe lung function disorders and pulmonary inflammation
}

\author{
Petra ReINHOLD ${ }^{1 *}$, Nathalie KIRSCHVINK ${ }^{2}$, Dirk TheEgARTEN ${ }^{3}$, \\ Angela BERNDT ${ }^{1}$

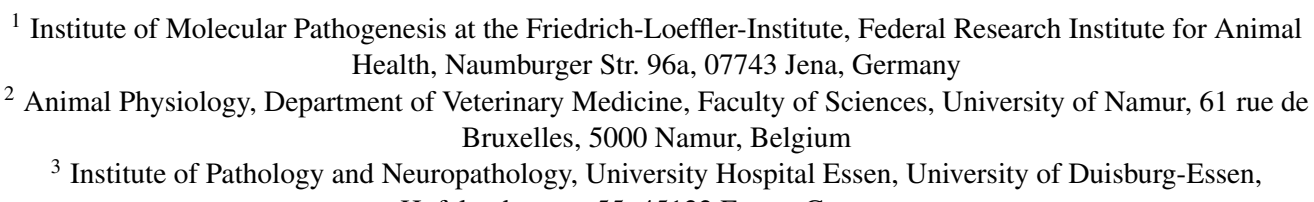 \\ Hufelandstrasse 55, 45122 Essen, Germany
}

(Received 31 October 2007; accepted 22 February 2008)

\begin{abstract}
This study was aimed at evaluating the pathophysiology of pulmonary dysfunctions and inflammatory consequences of an acute respiratory chlamydial infection induced experimentally in conventionally raised pigs (aged 39-44 days). Eight animals were exposed to Chlamydia suis (C. suis) and four non-infected animals served as controls. The total observation period was from seven days before challenge to seven days post exposure. While non-infected control pigs did not exhibit any clinical symptoms, animals exposed to $C$. suis developed fever and were severely respiratory distressed within the first week after exposure. After $C$. suis infection, pulmonary dysfunctions were characterised by a significant decrease in the diffusion capacity of the lung (i.e. transfer factor of the lung for carbon monoxide; TL CO), a significant increase in the functional residual capacity (FRC), and significant changes in the pattern of ventilation (respiratory rate increased while the tidal volume decreased). In exhaled breath condensate (EBC), leukotriene $\mathrm{B}_{4}\left(\mathrm{LTB}_{4}\right)$ and interleukin 6 (IL-6) showed a tendency to increase after infection. In the broncho-alveolar lavage fluid (BALF) of $C$. suis infected pigs, the activity of matrix metalloprotease 9 (MMP-9) was found to be increased compared to controls. BALF cytology was characterised by increased numbers of granulocytes and activated lymphocytes. Pulmonary inflammation in infected pigs was confirmed by post mortem histology. A prominent dissemination of chlamydial bodies in the lung was accompanied by an influx of macrophages, granulocytes and activated T-cells. Data obtained in this study provide new insight into the pathogenesis of acute respiratory chlamydial infections in pigs.
\end{abstract}

Chlamydia suis model / pulmonary inflammation / lung functions / exhaled breath condensate (EBC) / BALF

\section{INTRODUCTION}

The impact of Chlamydiaceae on animal health on pig farms is controversial because an inconsistency seems to exist between the obviously high prevalence of chlamydiae in

* Corresponding author: petra.reinhold@ fli.bund.de clinically normal swine herds $[4,5,10,41]$ and relatively few reports of acute clinical illness. Chlamydial infections in sows have been associated with reproductive disorders, the occurrence of MMA-syndrome (mastitis, metritis, agalactia), or perinatal mortality in piglets, and detection of chlamydiae in semen of boars suggests a potential for venereal 
transmission $[5,15,16]$. In addition, there is some data that chlamydioses in swine can be associated with enteritis, pneumonia, conjunctivitis, and pericarditis [22]. The knowledge about the involvement of Chlamydiaceae in the porcine respiratory disease complex is still limited and reports in the literature are very inconsistent. While lung function was not affected in symptom-free pigs with a naturally acquired presence of chlamydiae in the respiratory system [32], a clear pathogenic potential of Chlamydia species for the porcine respiratory system has been proven experimentally $[32,35]$.

According to current taxonomy, Chlamydia suis $(C$. suis), i.e. the former porcine serovar of $C$. trachomatis, has been identified as the major agent causing chlamydioses in swine [22]. However, there appears to be a high prevalence of mixed infections with C. abortus making it difficult to attribute clinical pathology to $C$. suis alone [10]. In order to evaluate the aetiological importance of $C$. suis, an experimental challenge model of aerosol infection was established by our group [38]. In contrast to the model described by Rogers et al. [35] where three day old gnotobiotic piglets were found to be susceptible to respiratory chlamydial infection, the pigs challenged in our model were conventionally raised, older (approximately six weeks), and had even a positive carrier status for chlamydiae [38]. Despite lower infection dosages compared to the model described by Rogers et al. [35], they responded to the aerosol challenge of $C$. suis with acute phase reactions, severe clinical signs and significant increases of chlamydiaspecific antibody titres [38]. Additionally, the present study was undertaken in order to clarify pathophysiological consequences of $C$. suis challenge particularly for the porcine respiratory system. Thus, (i) variables of lung function, (ii) markers of pulmonary inflammation measurable in exhaled breath, broncho-alveolar lavage fluid and on the cellular level, and (iii) immunohistochemical findings, as well as results of flow cytometric analysis, were evaluated in vivo and post mortem.

\section{MATERIALS AND METHODS}

\subsection{Animals}

Twelve colostrum-fed Deutsche Landrasse female pigs, conventionally raised on a farm with no animals being bought from outside, were provided by Charles River (Sulzfeld, Germany). At 3-4 weeks of age, they were brought into the animal house of the institute. They were included in the study after a quarantine period of at least ten days and confirmation of their clinically healthy status. Throughout the entire study, they were housed in conformity with the guidelines for animal welfare. Feeding was twice a day with a commercially available nutrition they received on the breeding farm. Water was supplied ad libitum. None of the feed contained antibiotics. The animals were kept in three groups, each consisting of four animals and housed separately.

\subsection{Study design}

At the age of 39-44 days, eight animals were exposed to $C$. suis and four non-infected animals served as controls. Each pig inhaled 35-40 L of aerosol produced either from $1.0 \mathrm{~mL}$ of chlamydia cell culture containing $10^{9}$ IFU per mL (strain DC6) or from non-infected culture. Aerosol was administered to each pig individually over a period of $10-15 \mathrm{~min}$. Details about aerosol production, aerosol administration and origin of the $C$. suis strain DC6 have been described previously [38].

Daily clinical observation focussed on feed intake, rectal temperature, respiratory rate and symptoms of diarrhoea or respiratory disorders, i.e. cough, nasal discharge or ocular secretions. Within a period ranging from seven days before challenge up to seven days after challenge, i.e. days post infection (dpi), pulmonary function tests, collection of blood samples and collection of exhaled breath condensate were performed as described below. A number was assigned to each pig. The tests each animal underwent are shown in Table I. Body weight was measured individually prior to each lung function test. The pigs were euthanised for necropsy at different time points (Tab. I). The study had ethical approval by the Commission for the Protection of Animals of the state of Thuringia.

\subsection{Protocol of pulmonary function testing}

Pulmonary functions were evaluated using MasterScreen Diffusion (Viasys Healthcare, 
Table I. Study design.

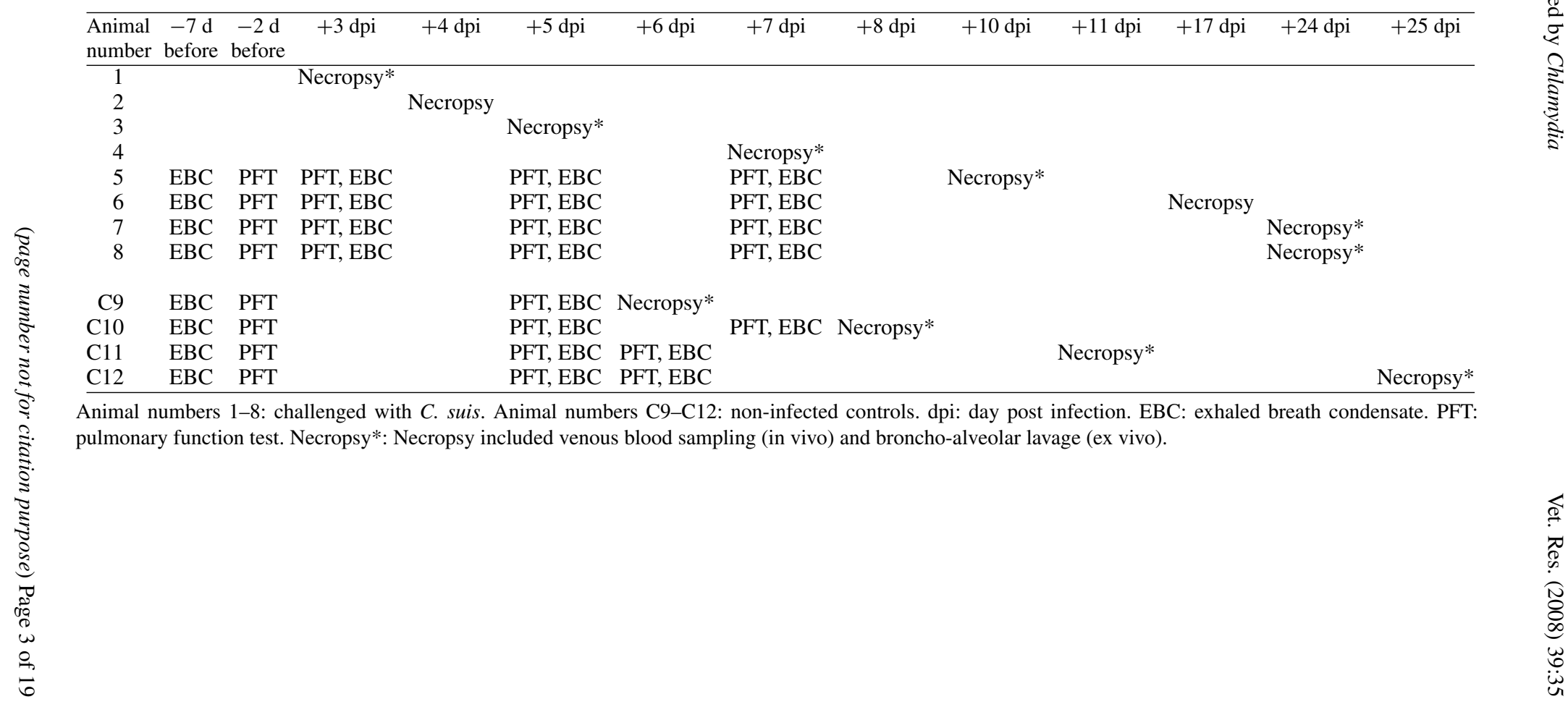


Hoechberg, Germany). Using different test gases, this system allows the simultaneous measure of static and dynamic lung volumes and variables describing the diffusion capacity of the lung. In order to evaluate the diffusion capacity of the lung, the transfer factor of the lung for carbon monoxide (TL CO) was determined according to the rebreathing (rb) method that is also known as the multiple breath or steady state method. The functional residual capacity (FRC) of the lung was measured by the multiple breath helium $(\mathrm{He})$ dilution technique (wash-in). In addition, airflow was measured during spontaneous breathing using a Lilly-type pneumotachograph (mesh resistance: $36 \mathrm{~Pa} /(\mathrm{L} / \mathrm{s}))$ and was used to calculate spirometric variables (i.e. tidal volume and respiratory rate).

All pulmonary function measurements were performed in sedated pigs (diazepam, $1.5-2.0 \mathrm{mg} / \mathrm{kg}$ body weight, intramuscularly) that were restrained using a canvas sling with openings for the limbs and were acclimated to the system individually using a tightly fitting facemask of appropriate size depending on the animal's head [18]. After an adaptation period of approximately $5 \mathrm{~min}$, the pig inhaled the test gas mixture (7-10\% helium (He), approximately $0.2-0.3 \%$ carbon monoxide (CO), $35 \%$ oxygen $\left(\mathrm{O}_{2}\right)$, rest nitrogen) from a $5 \mathrm{~L}$ reservoir bag. The rebreathing time varied between pigs and time points within the range $117-220 \mathrm{~s}$. All parameters were calculated automatically using the software included in the system. For further analysis, the following variables of pulmonary function were recorded:

- respiratory rate (RR),

- tidal volume (Vt),

- volume of minute ventilation $(\mathrm{V} \min =\mathrm{Vt} \times \mathrm{RR})$,

- transfer factor of the lung for carbon monoxide (TL CO rb),

- functional residual capacity of the lung (FRC).

\subsection{Collection of exhaled breath condensate samples}

The pig was sedated and restrained as for pulmonary function testing, and exhaled breath condensate (EBC) collection was performed immediately after pulmonary function when scheduled together. An EBC sampling system (ECoScreen, Viasys Healthcare) was connected to the facemask as previously described [30]. The animal was allowed to inhale only filtered ambient air (PALL breathing system filter, Pall Europe Ltd,
Portsmouth, UK) in order to avoid contamination of EBC by inhaled ambient particles. The total exhaled breath fraction of tidal breathing was condensed while passing through a non-re-breathing valve in the cooled collection system for at least $30 \mathrm{~min}$. EBC samples were removed from the collection system immediately after collection. Aliquots of the samples were prepared and were stored at $-80^{\circ} \mathrm{C}$, and analyses were performed within 12 weeks after collection.

\subsection{Necropsy, collection of broncho-alveolar \\ lavage fluid (BALF) and lung tissue samples}

Immediately before euthanasia, venous blood was collected in $7.5 \mathrm{~mL}$-syringes (S-Monovette ${ }^{\circledR}$, Sarstedt AG \& Co, Nuembrecht, Germany) for serum production from Vena jugularis in the nonfed animal. The trachea was exposed by dissection under conditions of deep anaesthesia (thiamylalsodium, $1 \mathrm{~g}$ per $50 \mathrm{~kg}$ body weight, intravenously). Large arterial forceps were applied to clamp the trachea and thus prevent contamination of the airways by aspiration of blood or gastric contents. Subsequently, the animal was exsanguinated via the Arteria axillaris, and the lung was removed. A broncho-alveolar lavage (BAL) was performed in the right basal lobe of the lung using a small catheter (that was instilled through the trachea) and glass syringes. Three consecutive washes using $10 \mathrm{~mL}$ for each installation of cold cell buffer $(140 \mathrm{mM} \mathrm{NaCl}, 2.8 \mathrm{mM} \mathrm{KCl}, 10 \mathrm{mM}$ $\mathrm{Na}_{2} \mathrm{HPO}_{4} \times 12 \mathrm{H}_{2} \mathrm{O}, 1.5 \mathrm{mM} \mathrm{KH_{2 }} \mathrm{PO}_{4}$; stored at $4{ }^{\circ} \mathrm{C}$ ), were performed per individual. After immediate aspiration, the recovered BAL-fluid was about $60 \%$. Immediately after BAL, lung tissue samples were taken from lesions and from macroscopically unchanged areas of the left caudal lung lobe for histopathological examinations.

\subsection{Analyses in EBC, BALF, and serum}

\subsection{1. $\mathrm{LTB}_{4}, \mathrm{IL-6}, \mathrm{IL-8}$ in $\mathrm{EBC}$}

In order to analyse the concentration of leukotrieneB $\mathrm{B}_{4} \quad\left(\mathrm{LTB}_{4}\right)$, a competitive enzyme immuno-assay (Cayman Chemical, Ann Arbor, USA) was used. Validated with LC/MS, the standard stem solution included in the commercial assay was dissolved in Milli-Q water for a concentration of $250 \mathrm{pg} / \mathrm{mL} \mathrm{LTB}_{4}$. This external standard was given on each microtiter plate on four different positions for control of validity of the plate. In 
addition, a calibration curve in the expected range of $\mathrm{LTB}_{4}$ concentration was performed by diluted standard solutions. The calibration curve was linear in the range of measurement. The analysis was performed using a reader for 96 well plates (Millenium Kinetik AnalyzerTM, DPC Biermann $\mathrm{GmbH}$, Bad Nauheim, Germany) with a filter at $\lambda=405 \mathrm{~nm}$ and a PC with software for photometers.

For measurement of interleukin 6 (IL-6), EBC samples were concentrated by lyophylisation $(500 \mu \mathrm{L}$ of each sample were dried and resuspended in $200 \mu \mathrm{L}$ diluents). Because no commercial test kit for porcine IL-6 was available, a special microtiter plate sandwich assay was created using the following commercial components: biotinylated anti-porcine IL-6 antibody (R\&D Systems, Minneapolis, USA, lot: CET01), anti-porcine IL-6 antibody (R\&D-Systems, lot: CBA01), recombinant porcine IL-6 (R\&D-Systems), and the colour reagent system "peroxidase hydrogen peroxide tetramethylbencidine" for detection (R\&DSystems). The reaction time was $30 \mathrm{~min}$ at room temperature. The reaction was stopped by sulphuric acid. The IL-6 standard dissolved in Milli-Q water was used for calibration. The detection limit of this assay was $10 \mathrm{pg} / \mathrm{mL}$. The calibration curve was linear.

The concentration of interleukin 8 (IL-8) was measured using an enzyme immune assay for porcine IL-8 (Trinova Biochem GmbH, Giessen, Germany, Lot: LO 80903) with a detection limit of $10 \mathrm{pg} / \mathrm{mL}$. The IL-8 standard dissolved in Milli-Q water was used for calibration. All measurements were performed in duplicate.

\subsubsection{Total protein and 8-iso-prostane in BALF}

The concentration of total protein in BALF was analysed colorimetrically using a Pierce Micro BCA $^{\text {TM }}$ Reagent Kit (Pierce, Rockford, USA). The reaction was measured by UV/VIS Spectrometer UNICAM UV2 and Software VISION V1.00 (Unicam Chromatography GmbH, Kassel, Germany). The sensitivity of this method was $\geq 0.5 \mu \mathrm{g} / \mathrm{mL}$, and the calibration curve was linear.

The concentration of 8-iso-prostane (8-IP) was analysed by EIA enzyme-immunoassay (Cayman Chemical Company), and the results were verified by means of LC/MS using an external 8-IP standard solution of $50 \mathrm{ng} / \mathrm{mL}$ (SIGMA-ALDRICH Chemie $\mathrm{GmbH}$, Taufkirchen, Germany). The detection limit was $\geq 3.9 \mathrm{pg} / \mathrm{mL}$. All measurements were performed in duplicate, and the means were used for further mathematical analysis. The ratio 8-IP/protein was calculated: 8-IP $(\mathrm{pg} / \mathrm{mL}) \times$ $1000 /$ total protein $(\mu \mathrm{g} / \mathrm{mL})$.

\subsubsection{Matrix metalloprotease activity in BALF and serum}

The activity of MMP-2 and MMP-9 was determined in serum and in the supernatant of BALF samples using zymography as previously described [14]. Electrophoretic migration and an incubation time of $18 \mathrm{~h}$ (serum) or $72 \mathrm{~h}$ (BALF) at $37^{\circ} \mathrm{C}$ after migration were used. After colouration, the gels were scanned and spots of lyses, expressed as arbitrary units of lysis, were measured.

\subsubsection{BALF cytology and cytometry}

Changes of immune cell composition of BALF were analysed by means of flow cytometry at five and seven days after $C$. suis infection. Briefly, BALF of two infected and two non-infected animals were centrifuged at $4{ }^{\circ} \mathrm{C}(300 \times g, 20 \mathrm{~min})$ and the sediment was washed with cold PBS. After determination of viability and cell number by trypan blue dye exclusion, $100 \mu \mathrm{L}\left(2 \times 10^{6}\right.$ cells $)$ of the respective cell suspensions were incubated with $50 \mu \mathrm{L}$ hybridoma culture supernatant of the monoclonal antibodies CD4a (clone 74-12-4; T-helper cells), CD8b (clone 11/295/33; cytotoxic T-cells), CD25 (clone $\mathrm{K}$ 231-3B2, activated T-cells), wSWC1a (clone 11/8/1; granulocytes, resting T-cells, monocytes, macrophages; all clones are kind gifts from Prof. Saalmüller, University of Veterinary Medicine, Vienna) or 2G6 (macrophages [2]) for $30 \mathrm{~min}$. After two washing steps, $20 \mu \mathrm{L}$ of FITC-conjugated goat anti-mouse immunoglobulin (dilution 1:10, Dako, Germany) were added and incubated for $30 \mathrm{~min}$ prior to analysis. Flow cytometry was performed with a FACScalibur flow cytometer (BD Bioscience, Heidelberg, Germany) equipped with a $15 \mathrm{~mW}$, $488 \mathrm{~nm}$ argon laser. The parameters "forward light scattering" (FSC), "sideward light scattering" (SSC) and fluorescence (FL1) were stored and processed using the CellQuest research software (BD Bioscience, Heidelberg, Germany). Cell debris was excluded and BALF cells were selected by their cell size (defined by FSC value) and granularity (defined by SSC value) using the FSC-SSC dot-plot diagram. 


\subsection{Morphology and histology of lung tissue}

Lungs were viewed macroscopically; representative specimens were taken and fixed in buffered $3.5 \%$ formaldehyde. Fixed lung tissue was embedded in paraffin wax (Tissuewax ${ }^{\mathrm{TM}}$; Medite $\mathrm{GmbH}$, Burgdorf, Germany), slides of 3-7 $\mu \mathrm{m}$ thickness were cut using a rotatory microtome (Microm $\mathrm{GmbH}$, Walldorf, Germany) and stained by hematoxylin and eosin (HE). Between four and nine representative microphotographs were taken of the slides of all animals using a Zeiss Axiophot with Axiocam and Axiovision 2 software (Carl Zeiss, Oberkochen, Germany) and critically reviewed.

Immediately after BAL, tissue samples of affected areas of the left caudal lung lobe as well as of the lung lymph node, tonsil and spleen were taken and frozen in liquid nitrogen until use.

To study the dissemination of chlamydial bodies in the lung, lung lymph node, tonsil and spleen as well as changes of the immune cell composition in the lung, frozen sections of tissue samples (two per animal and organ, $7 \mu \mathrm{m}$ in thickness) were prepared and subsequently stained immunohistochemically. They were fixed with acetone and incubated with the appropriate monoclonal antibodies against chlamydial lipopolysaccharide (LPS) (Chemicon, Hofheim, Germany), wSWC1a, CD2a (clone MSA4; T-cells), CD4a, CD8b, CD25 or $2 \mathrm{G6}$. For visualisation of bound antibodies, a staining kit (PAP, ChemMate Detection Kit, peroxidase anti-peroxidase, rabbit/mouse, DakoCytomation, Hamburg, Germany) was used according to the manufacturer's instructions. Negative control slides were incubated with pre-immune mouse serum (dilution 1:500) instead of the primary antibody. Sections were counterstained with haematoxylin and mounted with Canada balsam (Riedel de Haen AG, Seelze-Hannover, Germany).

\subsection{Statistical analysis}

Normally distributed data are given as mean \pm standard deviation (SD) whereas non-normally distributed data are always presented as median, minimum and maximum. For analysis of multiple data with normal distribution, multifactorial analysis of variance (ANOVA) was used, i.e. multiple range test based on least significant difference (LSD). To compare two unpaired samples, i.e. differences between two groups at one time point, the unpaired $t$-test was used for normally distributed data (comparison of means) while the Mann
Whitney Wilcoxon test (W-test) was used for data with unknown or non-normal distribution (comparison of medians). Since the given $P$ values are $\leq 0.05$, there is a statistically significant difference at the $95.0 \%$ confidence level in both tests. All confidence levels are given with the data.

\section{RESULTS}

\subsection{Clinical signs and body weight}

Non-infected control pigs did not exhibit any clinical signs during the study, but all animals exposed to $C$. suis showed clinical signs of an acute infection characterised by significantly elevated rectal temperatures (data not shown). Furthermore, severe dyspnoea, dry cough and serous nasal discharge were present. Dyspnoea in challenged pigs was accompanied by a spastic noise of breathing (wheezing), and by short breath breathing or breathlessness. However, neither ocular secretions nor diarrhoea was observed. Duration of respiratory symptoms was one week after exposure.

Body weight increased significantly in the control group from two days before infection to $7 \mathrm{dpi}(8.2 \pm 1.0 \mathrm{~kg}$ to $8.9 \pm 0.7 \mathrm{~kg}$; means $\pm \mathrm{SD} ; P \leq 0.05)$. In contrast, there was no significant increase in body weight in pigs exposed to $C$. suis for the same time period $(8.6 \pm 0.9 \mathrm{~kg}$ to $8.8 \pm 1.0 \mathrm{~kg} ;$ means $\pm \mathrm{SD}$; $P>0.05)$.

\subsection{Pulmonary functions}

Experimental exposure to $C$. suis significantly affected the pattern of ventilation (Fig. 1). Three days after exposure to $C$. suis, the mean tidal volume decreased by $50 \%$ to its minimum in the course of the study. Compared to baseline values, Vt remained significantly reduced until $7 \mathrm{dpi}$ in pigs challenged with $C$. suis, while it increased physiologically in control pigs. Due to a significant increase in respiratory rate (up to approximately 100 breathing cycles/min after $C$. suis exposure compared to a maximal respiratory rate of 32 breathing cycles/min in control animals at $3 \mathrm{dpi}$ ), the volume of minute ventilation was significantly increased and reached its 
Tidal Volume (Vt)

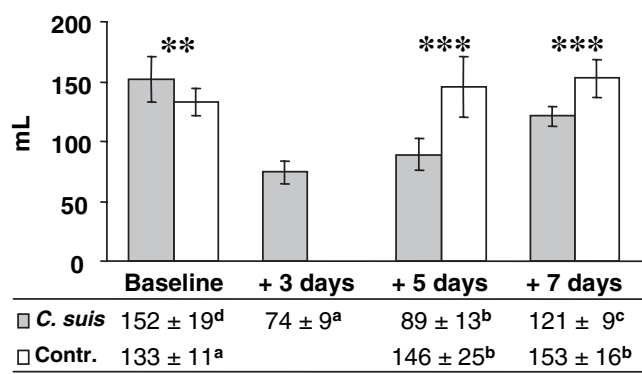

Volume of Minute Ventilation (Vmin)

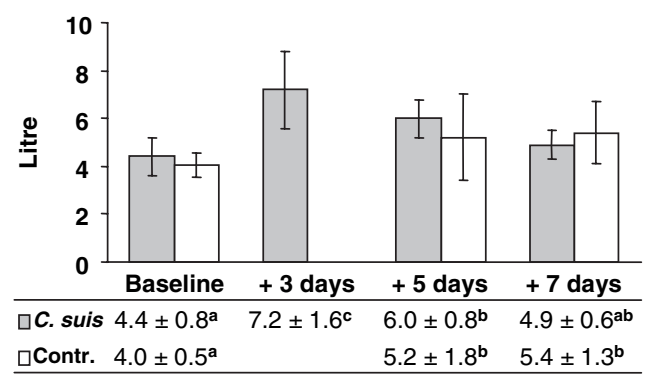

Figure 1. Means \pm standard deviations of tidal volume and minute volume in pigs experimentally exposed to $C$. suis and in non-infected controls. Different letters (a, b, c, d) indicate significant differences between time points within one group (ANOVA, LSD, $P \leq 0.01$ ). ${ }^{* *}$ Indicates significant differences between groups at one time point ( $t$-test, $P \leq 0.01)$; ***indicates significant differences between groups at one time point ( $t$-test, $P \leq 0.001)$.

maximum three days after $C$. suis exposure (Fig. 1).

The CO transfer factor of the lung increased continuously in control pigs. In contrast, it decreased significantly in pigs challenged with $C$. suis, showing its minimum 3 dpi (Fig. 2). Seven days after challenge, the values of $\mathrm{TL} \mathrm{CO} \mathrm{rb}$ were comparable to baseline values. As also shown in Figure 2, the functional residual capacity (FRC) did not change in control pigs. In pigs exposed to $C$. suis, however, it started to increase $5 \mathrm{dpi}$. Seven days after $C$. suis exposure, FRC was significantly increased to approximately $200 \%$ compared to baseline values.
TL CO rb

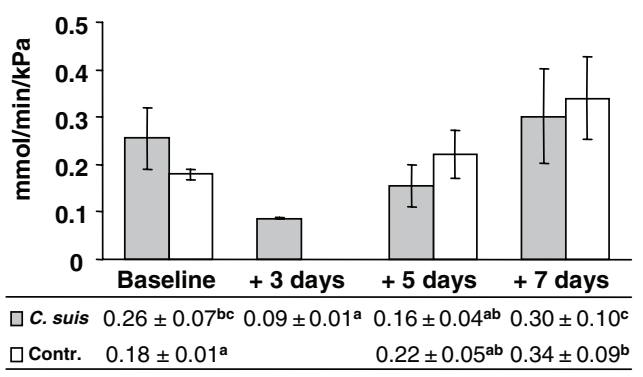

FRC (Helium)

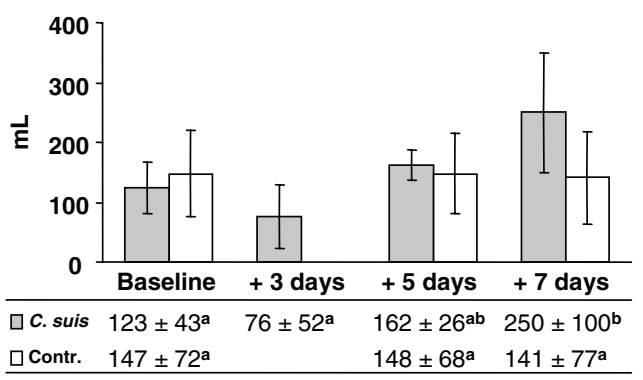

Figure 2. Means \pm standard deviations of COtransfer factor of the lung (TL CO rb) and functional residual capacity (FRC) in pigs experimentally exposed to $C$. suis and in non-infected controls. Different letters (a, b, c, d) indicate significant differences between time points within one group (ANOVA, LSD, $P \leq 0.01$ ).

\subsection{Markers of inflammation}

Figure 3 illustrates the concentrations of IL-6, IL-8, and $\mathrm{LTB}_{4}$ as measured in the EBC of pigs exposed to $C$. suis and non-infected controls. While IL-6 and LTB $_{4}$ showed a tendency to increase at least in some of the challenged pigs 5-7 dpi, no change was seen in IL-8.

Serum activity of MMP-2 and MMP-9 was similar in both groups prior to challenge and remained unchanged by either placebo or C. suis inhalation challenges. In BALF supernatant, MMP-9 was found to be increased in C. suis infected pigs compared to controls (Tab. II). Furthermore, the ratio between the concentration of 8-IP and the concentration of total protein in BALF (8-IP/protein) 

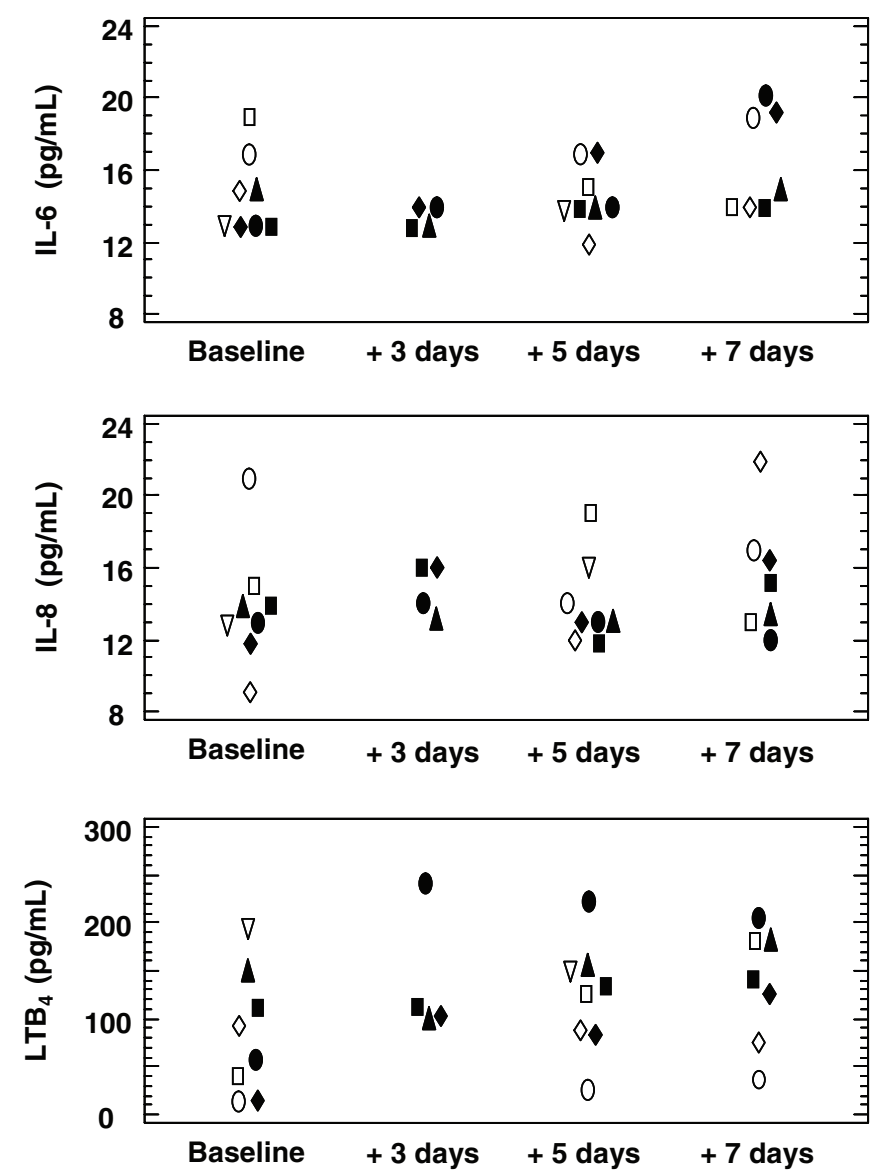

Figure 3. Concentration of interleukin-6 (IL-6), interleukin-8 (IL-8), and leukotrien $\mathrm{B}_{4}\left(\mathrm{LTB}_{4}\right)$ in exhaled breath condensate (EBC) samples collected from four pigs experimentally exposed to $C$. suis (filled symbols) and from four non-infected control pigs (empty symbols).

Table II. Activity of MMP-2 and MMP-9 (arbitrary units) in BALF and serum samples of pigs experimentally exposed to $C$. suis and non-infected controls.

\begin{tabular}{|c|c|c|c|c|c|c|c|}
\hline & \multicolumn{3}{|c|}{ Animals exposed to $C$. suis } & \multicolumn{3}{|c|}{ Controls } & \multirow[t]{2}{*}{$t$-test } \\
\hline & $\mathrm{n}$ & Mean & SD & $\mathrm{n}$ & Mean & SD & \\
\hline \multicolumn{8}{|c|}{ Blood (serum) } \\
\hline MMP-2 & 6 & 2923 & 1125 & 4 & 2418 & 1082 & n.s. \\
\hline MMP-9 & 6 & 3135 & 2393 & 4 & 2964 & 1734 & n.s. \\
\hline \multicolumn{8}{|l|}{ BALF } \\
\hline MMP-2 & 6 & 6399 & 2395 & 4 & 4927 & 3385 & n.s. \\
\hline MMP-9 & 6 & 6378 & 2767 & 4 & 1018 & 776 & $P<0.01$ \\
\hline
\end{tabular}

n.s.: No significant difference between groups. 


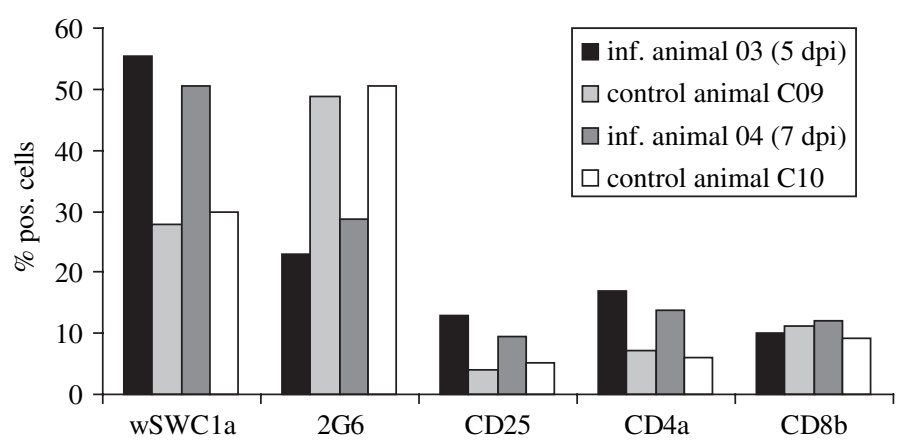

Figure 4. Cellular composition in broncho-alveolar lavage fluid (BALF) of two representative pigs euthanised 5 days and 7 days after challenge (animals 03 and 04: exposed to C. suis; animals C09 and C10: non-infected control). After exclusion of cellular debris, values are presented as \% positive cells in BALF.

was found to be significantly lower in pigs challenged with $C$. suis compared to controls $(130 \pm 71$ vs $280 \pm 103$, means $\pm \mathrm{SD}, t$-test, $P=0.03)$.

Taking all animals into account, neither the concentration of 8-IP nor the concentration of total protein in BALF differed significantly between groups. However, the following interesting time trend was seen for both markers: among all data, the highest absolute concentration of 8 -IP $(77.3 \mathrm{pg} / \mathrm{mL})$ and an extraordinary high amount of total protein $(1181 \mu \mathrm{g} / \mathrm{mL})$ were measured in the BALF of the single pig sacrificed three days after $C$. suis challenge. In the subsequent period (5-25 dpi), concentrations of both 8 -IP and total protein were lower and differed not significantly from control values (ranges for 8-IP: $30-38 \mathrm{pg} / \mathrm{mL}$ in controls, $27-69 \mathrm{pg} / \mathrm{mL}$ in $C$. suis; ranges for total protein: $96-414 \mu \mathrm{g} / \mathrm{mL}$ in controls; $110-526 \mu \mathrm{g} / \mathrm{mL}$ in C. suis).

\subsection{BALF cytology}

For characterisation of the immune cell composition of BALF upon chlamydial infection, different monoclonal antibodies against specific porcine antigens and flow cytometry were used. The results comparing two noninfected and two $C$. suis infected animals at five and seven days after challenge (time points of predominant pathological changes) are shown in Figure 4. The flow cytometric analysis revealed an increased number of $\mathrm{wSWC} \mathrm{a}^{+}$cells as well as of $\mathrm{CD}^{+}$ and $\mathrm{CD}_{25}^{+}$lymphocytes in the $C$. suis exposed animals, while the percentage of $2 \mathrm{G6}^{+}$macrophages declined. These results indicate the recruitment of granulocytes and activated T-cells after infection in BALF. Furthermore, the absolute cell number in BALF was about 2.5 times higher in pigs exposed to C. suis compared to control animals, and this finding indicates an absolute increase of all cell subsets including macrophages (data not shown).

\subsection{Histology of lung tissue}

\subsubsection{Histological pulmonary lesions}

Morphologic changes in lung tissue could be seen 3-10 dpi and were most conspicuous 4-6dpi. The lungs of all infected animals showed scattered consolidations with focal hyperinflation. Histologically, a bronchiolitis with lumens filled with inflammatory cells was seen on the third day (Fig. 5A). A severe focal pneumonia with interstitial infiltrates of lymphocytes, neutrophils, and eosinophils, intra-alveolar aggregates of macrophages and neurophils, as well as dystelectases, was found. Infiltrates were accompanied by a slight to moderate focal oedema, which was not involving the intra-alveolar spaces totally. Signs of diffuse alveolar damage with hyaline membranes were not seen. Inflammatory changes were progredient until the fifth day. After seven days (Fig. 5B), alterations were regressing. Ten days after infection (Fig. 5C) 

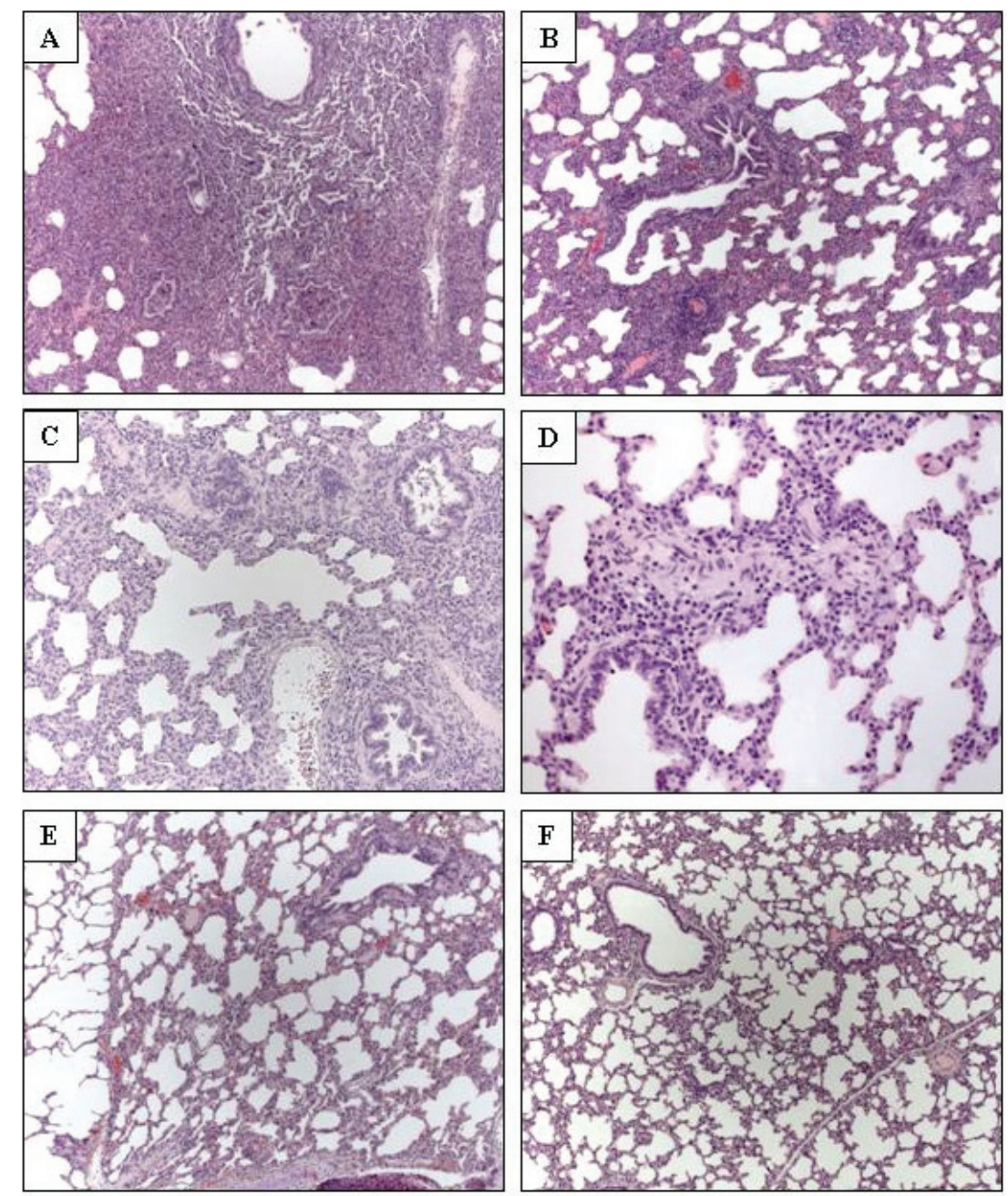

Figure 5. Pathohistology of porcine lung after C. suis infection (HE). (A) 3 dpi: floride bronchiolitis and severe focal pneumonia (animal 01; original magnification 40×). (B) 7 dpi: clear regression of inflammation (animal 04; original magnification $40 \times$ ). (C) $10 \mathrm{dpi}$ : interstitial infiltrates are still severe (animal 05; original magnification $100 \times$ ). (D) $17 \mathrm{dpi}$ : minimal oedema and slight perivascular infiltrates (animal 06; original magnification 200×). (E) 24 dpi: only focal minimal infiltrates but some hyperinflation (animal 07; original magnification $100 \times$ ). (F) Controls revealed only some focal infiltrates without relevance (animal C10; original magnification $12.5 \times)$.

interstitial infiltrates were still severe. Intramural infiltrates of the bronchioli were moderate, compressing the lumen and inducing dystelectases. On day 16 (Fig. 5D), only minimal oedema, slight perivascular infiltrates of lymphocytes, neutrophiles, eosinophiles, and some intra-alveolar aggregates of macrophages were found. After 23 days (Fig. 5E), only focal minimal infiltrates but some dystelectases could be detected. Controls revealed only some focal infiltrates as were seen 23 dpi (day 8 post inhalation, Fig. 5F) 
Table III. Occurrence of chlamydiae in organs of pigs experimentally exposed to C. suis and non-infected controls.

\begin{tabular}{|c|c|c|c|c|c|}
\hline$\overline{\mathrm{dpi}}$ & $\begin{array}{l}\text { Animal } \\
\text { number }\end{array}$ & Tonsil & Lung & $\begin{array}{l}\text { Lung lymph } \\
\text { node }\end{array}$ & Spleen \\
\hline 3 & 01 & n.d. & + & n.d. & n.d. \\
\hline 4 & 02 & + & + & - & - \\
\hline 5 & 03 & + & + & + & - \\
\hline 7 & 04 & + & + & + & - \\
\hline 10 & 05 & + & + & + & - \\
\hline 17 & 06 & + & + & + & - \\
\hline 24 & 07 & - & + & - & - \\
\hline 24 & 08 & - & + & - & - \\
\hline 6 & C09 & - & - & - & - \\
\hline 8 & C10 & - & - & - & - \\
\hline 11 & C11 & - & - & - & - \\
\hline 25 & $\mathrm{C} 12$ & - & - & - & - \\
\hline
\end{tabular}

+: Chlamydia-positive cells detectable; -: no detectable Chlamydia-positive cells, dpi: days post infection; n.d.: not done.

\subsubsection{Dissemination of Chlamydia suis}

To follow the dissemination of $C$. suis infection, cryostat sections of lung, lung lymph node, tonsil and spleen were immunohistochemically stained with an anti-chlamydia-LPS antibody and analysed by light microscopy concerning the occurrence and localisation of chlamydial bodies. As shown in Tables III and IV, chlamydiae were found in the lungs of all infected animals as well as in tonsils and lung lymph nodes of pigs 4-17 dpi. While single infected cells and a few sporadic detections in sinusoids and germinal

Table IV. Occurrence of BALT and predominance of chlamydiae in lung tissue of pigs experimentally exposed to $C$. suis and non-infected controls.

\begin{tabular}{|c|c|c|c|c|c|c|c|}
\hline dpi & $\begin{array}{l}\text { Animal } \\
\text { number }\end{array}$ & BALT & $\begin{array}{l}\text { Bronchial } \\
\text { epithelium }\end{array}$ & $\begin{array}{l}\text { Cells of } \\
\text { alveoli and } \\
\text { bronchi }\end{array}$ & Interstitium & $\begin{array}{c}\text { Histiocytes } \\
\text { (peribronchial, } \\
\text { perivascular) }\end{array}$ & $\begin{array}{c}\text { Septal } \\
\text { fibroblasts }\end{array}$ \\
\hline 3 & 01 & - & + & ++ & ++ & - & - \\
\hline 4 & 02 & - & + & +++ & +++ & - & + \\
\hline 5 & 03 & $x \times$ & - & ++ & ++ & - & + \\
\hline 7 & 04 & $x$ & - & + & + & - & + \\
\hline 10 & 05 & $x$ & - & + & + & + & + \\
\hline 17 & 06 & - & - & + & + & + & + \\
\hline 24 & 07 & - & - & + & + & - & - \\
\hline 24 & 08 & $x$ & - & + & + & + & + \\
\hline 6 & C09 & - & - & - & - & - & - \\
\hline 8 & $\mathrm{C} 10$ & - & - & - & - & - & - \\
\hline 11 & C11 & - & - & - & - & - & - \\
\hline 25 & $\mathrm{C} 12$ & - & - & - & - & - & - \\
\hline
\end{tabular}

$\times$ : BALT present; $\times \times$ : BALT more frequently present +++ : high number of Chlamydia-positive cells; ++ : moderate number of chlamydia-positive cells; +: low number of Chlamydia-positive cells; -: no detectable Chlamydia-positive cells/BALT. 

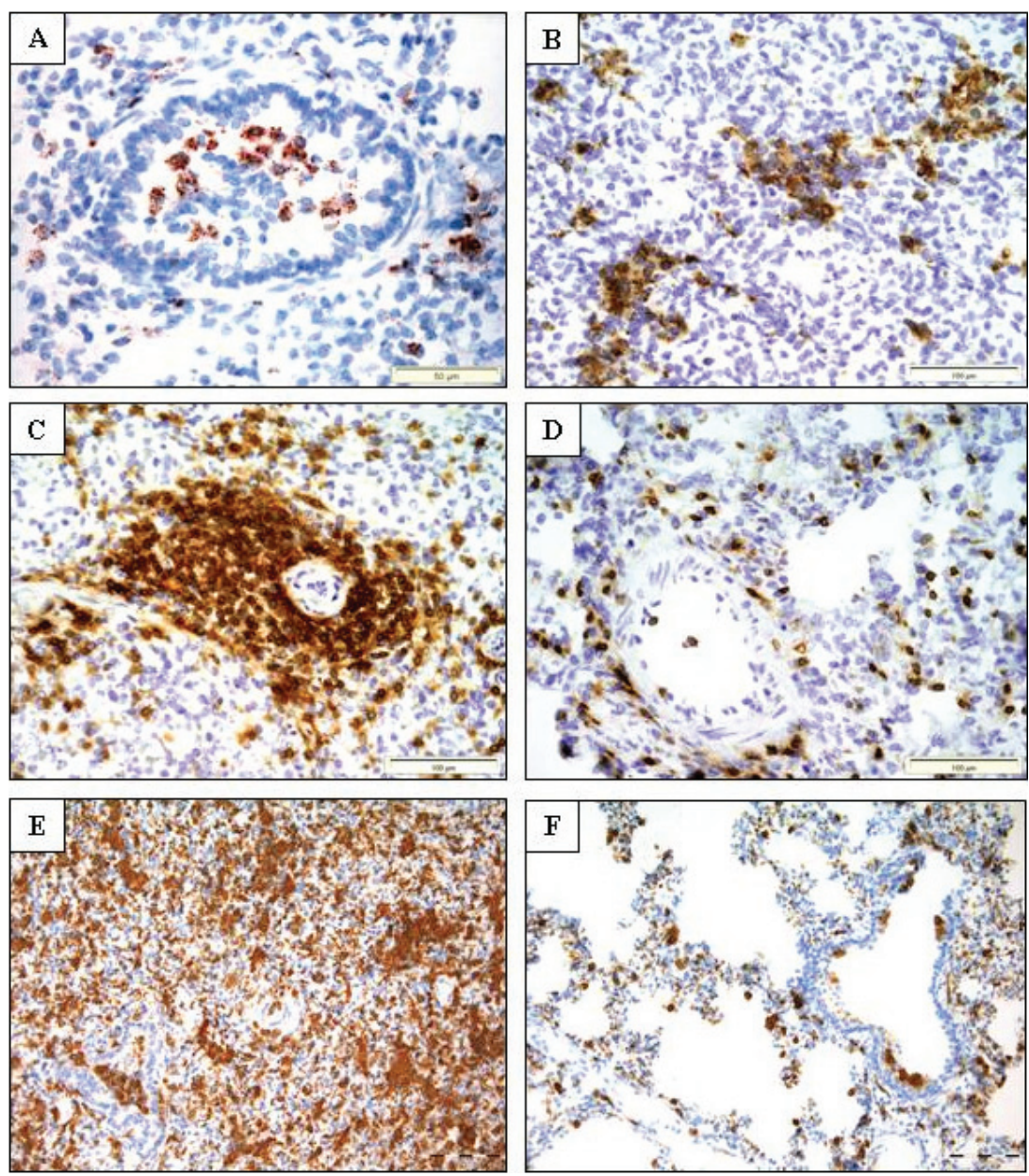

Figure 6. Lung tissue sections of infected (A, B, C, E) and control (D, F) animals immunohistochemically stained (brown) for chlamydiae (A, B), CD2a $\mathrm{a}^{+}$T-cells (C, D) and $2 \mathrm{G}^{+}$macrophages (E, F). (A) Cells fulfilled with chlamydial bodies localised in a bronchioli ten days after $C$. suis exposure (animal 05). (B) Chlamydia infected areas localised in the interstitium three days after $C$. suis exposure (animal 01). (C) T-cells localised perivascularly four days after $C$. suis exposure (animal 02). (D) T-cells in lung tissue of a non-treated control animal (animal C12). (E) Lung tissue closely packed, alveoli filled with macrophages and compressed bronchioli in the lung obtained three days after $C$. suis exposure (animal 01). (F) Wide open alveoli in the lung of a non-infected control animal (animal C12).

centres dominated in lung lymph nodes and tonsils, chlamydiae were highly prominent and visible as larger focal infections in the respiratory tract. Especially pronounced 3-5 dpi, chlamydial bodies were detected in the interstitium and alveolar as well as bronchial spaces of the lung (Tab. IV; Figs. 6A and 6B). Cells of bronchial epithelium were sparsely chlamydia-positive at $3 \mathrm{dpi}$ and $4 \mathrm{dpi}$. Later on, chlamydiae were additionally found in histiocytes of peribronchial and perivascular regions $(10-24 \mathrm{dpi})$ as well as in septal fibroblasts (4-24 dpi; Tab. IV). In control pigs, chlamydiae were never observed.

Notably, BALT was seen in the lungs of some $C$. suis infected animals, but not in

Page 12 of 19 (page number not for citation purpose) 
Table V. Occurrence of different immune cell subsets in lung tissue of pigs experimentally exposed to C. suis and non-infected controls.

\begin{tabular}{rccccccc}
\hline dpi & $\begin{array}{c}\text { Animal } \\
\text { number }\end{array}$ & wSWC1a & 2G6 & CD2a & CD4a & CD8b & CD25 \\
\hline 3 & 01 & ++++ & +++ & ++ & + & ++ & + \\
4 & 02 & +++ & ++++ & +++ & +++ & ++ & ++ \\
5 & 03 & ++++ & ++++ & ++++ & ++++ & +++ & +++ \\
7 & 04 & ++ & +++ & ++++ & +++ & +++ & ++ \\
10 & 05 & ++ & +++ & ++++ & ++++ & +++ & ++ \\
17 & 06 & ++ & +++ & +++ & ++ & +++ & ++ \\
24 & 07 & ++ & ++ & ++ & + & ++ & + \\
24 & 08 & ++ & ++ & ++ & + & ++ & + \\
& & & & ++ & + & + & ++ \\
6 & C09 & ++ & ++ & ++ & + & ++ \\
8 & C10 & ++ & ++ & +++ & ++ & ++ & $(+)$ \\
11 & C11 & ++ & ++ & ++ & + & ++ & $(+)$ \\
25 & C12 & ++ & ++ & ++ & + & ++ & $(+)$ \\
\hline
\end{tabular}

++++ : Very high number of positive cells; +++ : high number of positive cells; ++ : moderate number of positive cells; + : low number of positive cells; $(+)$ : very low number of positive cells.

control animals (Tab. IV). Especially, one animal (No. 3; 5 dpi) showed very developed BALT with distinct follicle centres and T-cell areas. BALT was preferentially located around bronchioli and small bronchi.

\subsubsection{Emergence of immune cells in lung}

To study the immune response of the lung, cryostat sections of all animals were immunohistochemically stained with different monoclonal antibodies against immune-relevant cells and evaluated by an individual scoring system. The results are summarised in Table V and representative pictures are shown in Figures $6 \mathrm{C}-6 \mathrm{~F}$.

Compared to control animals, a clear increase in all investigated immune cell subsets was seen upon $C$. suis exposure. While the highest number of $\mathrm{wSWCla}^{+}$cells was observed 3-5 dpi, the number of other immune cell subsets was initially elevated at $4 \mathrm{dpi}$ and continued up to $10 \mathrm{dpi}$ or $17 \mathrm{dpi}$ in dependence of the detected antigen.

Quantitative changes of $2 \mathrm{G6}^{+}$macrophages were especially prominent and impressive 4-5 dpi in lung tissue. Large numbers of macrophages were filling the alveoli and widening the alveolar septa leading to a closely packed appearance of lung tissue.

Elevated numbers of T-cells were predominantly localised in peribronchial and perivascular regions but also in the interstitium of chlamydia-affected lung areas. Notably, the number of $\mathrm{CD}^{+}{ }^{+}$and $\mathrm{CD} 25^{+} \mathrm{T}$-cells increased in the lung tissue of exposed pigs.

\section{DISCUSSION}

\subsection{Evaluation of pulmonary dysfunctions}

In control pigs, neither FRC nor the pattern of respiration changed, and continuous increases of TL CO rb, Vt and Vmin must be considered as physiological due to the growthrelated increase in body weight in the course of the study (see Section 3.1.). In contrast, aerosol $C$. suis infection resulted in significant deterioration in pulmonary functions at the same time as clinical signs reached their maxima (3-5dpi). Diminution of the $\mathrm{O}_{2}$ diffusion capacity of the lung (i.e. reduced TL CO rb) indicates severe impairment of the $\mathrm{O}_{2}$ transport from the lung into the blood that might be caused by (i) alteration in the lung fluid balance leading to pulmonary 
oedema, (ii) alveolar hypoventilation, or (iii) a mismatching between ventilation and perfusion.

\subsubsection{Pulmonary oedema}

In the early acute phase ( $3 \mathrm{dpi})$, a higher permeability of the lung capillary barrier contributed most likely to the reduced diffusion capacity of the lung as indicated by an extraordinary high concentration of total protein in BALF $(>1000 \mu \mathrm{g} / \mathrm{mL})$ and confirmed histologically by focal oedema. In animals sacrificed later (until 24 days after challenge), there was no more evidence for protein leakage into alveoli showing a rapid reversibility of lung capillary barrier disorders.

\subsubsection{Alveolar hypoventilation and inhomogeneities between ventilation $(V)$ and perfusion $(Q)$}

The enormous decrease in tidal volume 3-5 dpi indicates that the volume in- and expired per breath was reduced to up to $50 \%$, leading to the consequence of reduced alveolar ventilation and alveolar hypoxia. Pathogenetically, this was most likely caused by both peripheral airway obstructions (bronchospasms) and reduced pulmonary compliance as observed in an earlier study using the same model [32]. Because the porcine lung lacks collateral airways to ventilate the lung periphery of obstructive regions through pathways for collateral airflow [24], atelectases develop frequently in any obstructive conditions leading to ventilatory asynchronisms, i.e. regional inhomogeneities in alveolar ventilation [34]. In addition, inhomogeneities in alveolar ventilation are regularly involved in V-Q inhomogeneities due to the high degree of compartmentalisation of the porcine lung.

All pathogenetic features discussed above were very likely involved in the diminution of $\mathrm{O}_{2}$ diffusion capacity and contributed to reduced lung gas exchange, and consequently to a reduced oxygen supply to the arterial blood (arterial blood gas analysis was not performed in this study). To compensate for arterial oxygen deficiency, the respiratory frequency increased significantly leading to an increase in minute ventilation. Due to the reduced tidal volume and the increased respiratory frequency, the pattern of respiration changed to rapid and shallow breaths in experimentally infected pigs. Within one week after exposure, infected pigs tended toward a clinical recovery and both diffusion capacity of the lung and minute ventilation were returned to baseline values indicating that gas exchange was normalised at $7 \mathrm{dpi}$.

\subsubsection{Emphysema}

One week after challenge, FRC (i.e. the volume of gas remaining in the lung at the end of expiration) was doubled in comparison to the baseline in pigs challenged with $C$. suis, and the pattern of breathing was still characterised by a significantly decreased tidal volume and a significantly increased respiratory rate. The continuous increase of FRC as observed between day 5 and day 7 after challenge might be suggestive of trapped air or the development of pulmonary emphysema. Pathogenetically, this phenomenon is supported by earlier observations showing that airflow limitations due to peripheral airway obstructions do affect expiration much more than inspiration in C. suis infected pigs [32]. Whether peripheral airway obstruction and the developing obstructive emphysema as observed one week after infection are reversible, or whether these phenomena represent an early stage that tends towards chronic airway obstruction, deserves further examination in a longer study period.

\subsection{Biochemical evaluation of pulmonary inflammation}

Biochemical markers to evaluate pulmonary inflammation were measured in EBC (collected in vivo within the first week after challenge) and BALF (collected ex vivo until 24-25 dpi). Independent of the different time courses, EBC and BALF are not directly comparable diagnostic media [13]. The collection of EBC has the advantage of being completely non-invasive, repeatable and does not require patient cooperation. Although a variety of 
mediators measurable in EBC has been described as being influenced by several diseases of airways or lung parenchyma $[17,31]$ its diagnostic potentials and limitations have yet to be defined in both human and veterinary medicine [11]. BAL, a well accepted diagnostic tool in humans as well as in animals, has the disadvantage when performed in vivo to cause an influx of neutrophils and alterations in lung surfactant that may last for three weeks [23]. Consequently, BAL was only performed ex vivo in this study in order to avoid any interference with pulmonary function measurements.

\subsubsection{Exhaled breath condensate}

LTB $_{4}$ and IL-6 showed a tendency to increase in some pigs challenged with $C$. suis, while no change was seen in the concentration of IL-8 within the first week after infection. The increase of $\mathrm{LTB}_{4}$, an inflammatory mediator with chemotactic activity for neutrophils and other cell types, was in agreement with previous findings in calves demonstrating that elevated $\mathrm{LTB}_{4}$ concentrations in EBC due to respiratory infections were correlated with deteriorations of pulmonary functions [33]. IL-6 is a cytokine that is involved in acute phase, and acute phase response has been evaluated previously [38]. Information about mediators or markers of inflammation as measured in EBC in this study are interesting but should be considered as preliminary results.

\subsubsection{Broncho-alveolar lavage fluid}

While 8-IP, a stable peroxidative product deriving from arachidonic acid, was measured in BALF to reflect oxidative stress, the concentration of protein was used to evaluate the permeability of the lung capillary barrier. Three days after $C$. suis challenge, the highest concentration of total protein as well as 8-IP was measured indicating that both (i) leakages in the alveolo-capillary barrier and (ii) a certain amount of oxidative stress were present at the same time. These processes were reversible because concentrations of 8-IP and total protein were not significantly different from those measured in BALF of control pigs in the period 5-25 dpi. Interestingly, the ratio between the concentration of 8-IP and the concentration of total protein in BALF (8-IP) protein) was found to be sensitive to reflect pulmonary inflammation, a finding that has not been described before.

Data for metalloproteinases suggest that acute respiratory $C$. suis infection induced activation of pulmonary MMP-9 but not MMP-2 in pigs. Systemic repercussions on serum MMP-2 and MMP-9 activity were not detected. The absence of a systemic effect parallels findings made in calves with chronic chlamydial infections [14]. Interestingly, chlamydia-infected calves showed a significant increase of MMP-2 activity in BALF, which paralleled subclinical and chronic inflammatory obstructive changes of airways [14]. In the present model of acute pulmonary infection, however, BALF MMP-2 activity remained unchanged in comparison to the control animals, whilst MMP-9 activity increased significantly. These differences might be attributed to the acute character of this infectious model, where large numbers of inflammatory cells, including neutrophils and macrophages, were detected cytologically and histologically. Both neutrophils and macrophages were reported to produce and secrete MMP-9 upon an acute stimulation, whilst MMP-2 is considered as an indicator of fibroblastic activity suggestive of remodelling [40].

In an earlier publication of our group, a significant increase of heat shock protein 60 (Hsp60) was described in the serum of C. suis infected pigs [38]. Although no data about Hsp60 within the respiratory tract are available for this earlier study, the increase of Hsp60 in response to $C$. suis infection merits attention. Indeed, it has been shown in murine macrophages that MMP-9 expression and MMP-9 activity increase in response to chlamydial infection as well as in response to chlamydia-induced Hsp60. Inactivation of chlamydial Hsp60 by heat prevented MMP-9 expression, suggesting that Hsp60 might mediate the expression of this proteolytic enzyme [19]. Another study reports that monocyte MMP-9 expression can be upregulated 
by Hsp70 overexpression, which increases the activity of transcription factor nuclear factor $\kappa \mathrm{B}(\mathrm{NF}-\kappa \mathrm{B})$ activating factor 1 (AP-1) [21]. These in vitro data support observations made in humans, where the inflammatory responses initiated by chlamydia-specific Hsp appear to play a role in the pathogenesis of asthma [9, 12, 39, 43]. Accordingly, long-term investigations would be interesting in order to describe the relationship between chlamydial infection, Hsp, MMP expression and activities and pulmonary inflammation in vivo.

\subsection{Dissemination of $C$. suis, histology and immune response}

In former studies using nested PCR, DNA of $C$. suis was detected in the lung as well as in tonsils, lung lymph nodes and spleen [38]. Using immunohistochemistry, only a few chlamydia-positive cells were found in lung lymph nodes and tonsils while the lung presented highly impressive infection foci. This, together with the absence of chlamydiae in the spleen, argues for a rather local infection process mainly restricted to the lung. However, the number of chlamydial bodies occurring seems to be very different in the organs as shown in the present study. The ability of chlamydiae to leave the respiratory tract and cause infections of non-respiratory sites has been demonstrated by other authors for $C$. pneumoniae [8]. As specified, alveolar macrophages transport chlamydiae to the peribronchiolar lymphatic tissue and subsequently the pathogen enters organs via dissemination by peripheral blood monocytes [8]. A predominance of $C$. suis in porcine alveolar macrophages and histiocytes was demonstrated in the present study as well as by confocal laser-scanning microscopy [38].

Unexpectedly, chlamydia-stained bronchial epithelial cells were hardly found in our study. This result indicates an acute respiratory disturbance and is in line with other reports on acute chlamydial infections [37]. In contrast, the bronchiolar epithelium was chlamydiapositive for up to eight weeks in chronic chlamydial infection [8]. Whether there are really different target cells in acute and chronic pulmonary C. suis infection, and how a chronic infection can result from an acute one, has to be further investigated. However, chlamydiae may enter the body rather by the alveoli than through the bronchial epithelium in acute infection, which might be facilitated by the hyperinflated and/or damaged squamous cell lining of alveoli in the course of disease.

The histologically assessed infiltration of granulocytes, macrophages and lymphocytes, as well as the dynamic of inflammatory changes, were confirmed and specified. Granulocytes and macrophages (cells of innate immunity) appeared early after infection. In vitro experiments demonstrated that macrophages interact with chlamydiae [20]. On the one hand, the obligate intracellular chlamydiae can survive and proliferate inside of these cells. On the other hand, macrophages are equipped with the capability to eliminate intracellular pathogens. However, chlamydiae may benefit from a rapid invasion of macrophages for their own multiplication and perhaps transportation into extra-inflammatory sites in vivo. In this way, the elicited immune response does not only play a role in eradication but also in the pathogenesis of that intracellular agent.

The detailed immunohistochemical analysis and flow cytometry proved the involvement of T-cells, especially $\mathrm{CD}^{+}{ }^{+}, \mathrm{CD}^{+}$and $\mathrm{CD} 25^{+} \mathrm{T}$-cells, in the pulmonary host defence against $C$. suis. Altogether, the results of this acute aerogeneous $C$. suis infection indicate a more Th1-related immune response in swine. That cell-mediated immune mechanisms are of special importance in chlamydial infections of the lung has been shown by other authors [28, 29, 42].

\subsection{Involvement of lipopolysaccharide (LPS) in the pathogenesis}

Since LPS produced by gram-negative bacteria may play a significant role in acute respiratory failure in vivo and because endotoxin associated changes in the lung share some features with observations of this study, the possible contribution of chlamydial LPS to the 
pathogenetic complexity of this study needs to be discussed. In porcine models of endotoxemia or sepsis, a significantly increased concentration of total protein in BALF was one of the most reproducible findings $[3,26$, $27,44]$, and increased vascular permeability leading to extra-vascular lung fluid, pulmonary oedema and protein leakage into alveoli has been described as a typical response [3, 25]. With respect to lung functions, a reduced pulmonary compliance was found to be a useful early assessment of evolving lung injury after onset of sepsis [3]. Furthermore, the porcine lung responses to endotoxin primarily by increased perfusion heterogeneity and redistributed perfusion between lung regions $[6,7]$ and marked pulmonary vasoconstriction leads to pulmonary hypertension and increased pulmonary vascular resistance [26, 27, 44]. The increase of IL-6, an endogenous mediator of LPS-induced fever, might also be related to the presence of chlamydial LPS in the infected pigs, and the lack of IL-8 response corresponds to data reported from humans, where IL-8 did not show a significant change in a human model of inhaled LPS exposure [36]. Last but not least, a significant increase of the lipopolysaccharide binding protein (LBP) in the peripheral blood of C. suis infected pigs was observed 3-5dpi using the same model [38]. At this stage of research, it would be speculative to distinguish to what extent inflammation and lung function disorders were predominantly caused by chlamydial LPS versus the establishment of a replicative infection. Interactions between LPS and the lung have not been fully understood and signalling pathways remain to be clarified even in human medicine [1]. Further studies with the application of heat-inactivated chlamydiae at the same dose will allow the differentiation of direct LPS and infection-related effects.

\section{CONCLUSIONS}

Data of this study demonstrate that consequences of an experimentally induced $C$. suis infection in pigs comprise complex interactions between cellular responses within the lung, pulmonary inflammation, and pulmonary function disorders leading pathophysiologically to gas exchange disturbances and clinically to respiratory distress and losses in body weight increase. Data obtained in this study provide new insight into the pathogenesis of acute respiratory chlamydial infections. This large animal model appears suitable for further investigations of chlamydial respiratory infections and can be recommended for studies of chlamydia-associated infections of the human lung.

Acknowledgements. The authors thank Dr Ernst Grossmann and Dr Konrad Sachse for collaboration. They are very thankful to Annelie Langenberg, Sylke Stahlberg, Gerhard Födisch and to all colleagues working in the team of the animal house (FLI Jena, Germany) for their skilful assistance while performing the numerous pulmonary function tests during the study. In addition, they are grateful to Dr Michael Rothe and Dr Gunter Becher (FILT GmbH, Berlin, Germany) for analysing $\mathrm{LTB}_{4}$, IL-6, and IL-8 in EBC samples as well as total protein and 8-IP in BALF samples. They also thank Katrin Schlehahn (FLI Jena, Germany), Laetitia Wiggers (University of Namur, Belgium), Carina Kruip and Nellia Schatz (RuhrUniversity Bochum, Germany) for excellent technical assistance and support in the different laboratories. Help and assistance given by Heike Friedrich (FLI, Jena) in preparing the manuscript is very much appreciated. Furthermore, the authors wish to express their gratitude to Dr Michael Scott Davis (Oklahoma State University, USA) for his critical reading of the manuscript.

\section{REFERENCES}

[1] Bals R., Lipopolysaccharide and the lung: a story of love and hate, Eur. Respir. J. (2005) 25:776-777.

[2] Berndt A., Heller M., Methner U., Kosmehl H., Müller G., Monoclonal antibodies against porcine macrophages, Vet. Immunol. Immunopathol. (2000) 74:163-177.

[3] Byrne K., Cooper K.R., Carey P.D., Berlin A., Sielaff T.D., Blocher C.R. et al., Pulmonary compliance: early assessment of evolving lung injury after onset of sepsis, J. Appl. Physiol. (1990) 69:22902295.

[4] Camenisch U., Lu Z.H., Vaughan L., Corboz L., Zimmermann D.R., Wittenbrink M.M., Pospischil A., Sydler T., Diagnostic investigation into the role of Chlamydiae in cases of increased rates of return to oestrus in pigs, Vet. Rec. (2004) 155:593-596.

[5] Eggemann G., Wendt M., Hoelzle L.E., Jager C., Weiss R., Failing K., Prevalence of Chlamydia infections in breeding sows and their importance 
in reproductive failure, Dtsch. Tierarztl. Wochenschr. (2000) 107:3-10.

[6] Gerbino A.J., Altemeier W.A., Schimmel C., Glenny R.W., Endotoxemia increases relative perfusion to dorsal-caudal lung regions, J. Appl. Physiol. (2001) 90:1508-1515.

[7] Gerbino A.J., McKinney S., Glenny R.W., Correlation between ventilation and perfusion determines VA/Q heterogeneity in endotoxemia, J. Appl. Physiol. (2000) 88:1933-1942.

[8] Gieffers J., van Zandbergen G., Rupp J., Sayk F., Krüger S., Ehlers S., Solbach W., Maass M., Phagocytes transmit Chlamydia pneumoniae from lung to the vasculature, Eur. Respir. J. (2004) 23:506510 .

[9] Hahn D.L., Peeling R.W., Dillon E., McDonald R. Saikku P., Serologic markers for Chlamydia pneumoniae in asthma, Ann. Allergy Asthma Immunol. (2000) 84:227-233.

[10] Hoelzle L.E., Steinhausen G., Wittenbrink M.M., PCR-based detection of chlamydial infection in swine and subsequent PCR-coupled genotyping of chlamydial omp1-gene amplicons by DNA-hybridization, RFLP-analysis, and nucleotide sequence analysis, Epidemiol. Infect. (2000) 125:427-439.

[11] Horváth I., Hunt J., Barnes P.J., Alving K., Antczak A., Baraldi E., et al., Exhaled breath condensate: methodological recommendations and unresolved questions, Eur. Respir. J. (2005) 26:523-548.

[12] Huittinen T., Hahn D., Anttila T., Wahlström E., Saikku P., Leinonen M., Host immune response to Chlamydia pneumoniae heat shock protein 60 is associated with asthma, Eur. Resp. J. (2001)17:10781082.

[13] Jackson A.S., Sandrini A., Campbell C., Chow S., Thomas P.S., Yates D.H., Comparison of biomarkers in exhaled breath condensate and broncho-alveolar lavage, Am. J. Respir. Crit. Care Med. (2007) 175:222227.

[14] Jaeger J., Liebler-Tenorio E., Kirschvink N., Sachse K., Reinhold P., A clinically silent respiratory infection with Chlamydophila spp. in calves is associated with airway obstruction and pulmonary inflammation, Vet. Res. (2007) 38:711-728.

[15] Kauffold J., Melzer F., Berndt A., Hoffmann G., Hotzel H., Sachse K., Chlamydiae in oviducts and uteri of repeat breeder pigs, Theriogenology (2006) 66:1816-1823.

[16] Kauffold J., Melzer F., Henning K., Schulze K., Leiding C., Sachse K., Prevalence of chlamydiae in boars and semen used for artificial insemination, Theriogenology (2006) 65:1750-1758.
[17] Kharitonov S.A., Barnes P.J., Exhaled biomarkers, Chest (2006) 130:1541-1546.

[18] Klein C., Reinhold P., Analysis of respiratory mechanics by impulse oscillometry in non-sedated and diazepam-sedated swine, Res. Vet. Sci. (2001) 70:181189

[19] Kol A., Sukhova G.K., Lichtman A.H., Libby P., Chlamydial heat shock protein 60 localizes in human atheroma and regulates macrophage tumor necrosis factor- $\alpha$ and matrix metallo proteinase expression, Circulation (1998) 98:300-307.

[20] La Verda D., Byrne G.I., Interactions between macrophages and chlamydiae, Immunol. Ser. (1994) 60:381-399.

[21] Lee K.J., Kim Y.M., Kim D.Y., Jeoung D., Han K., Lee S.T., Lee Y.S., Park S.H., Park J.H., Kim D.J., Hahn J.H., Release of heat shock protein 70 (Hsp70) and the effects of extracellular Hsp70 on matric metalloproteinase-9 expression in human monocytic U937 cells, Exp. Mol. Med. (2006) 38:364-374.

[22] Longbottom, D., Chlamydial infections of domestic ruminants and swine: new nomenclature and new knowledge, Vet. J. (2004) 168:9-11.

[23] Loos U., Labedzki L., Weiss J.M., Schädigung des pulmonalen Surfactant Systems nach bronchoalveolärer Lavage? Prax. Klin. Pneumol. (1987) 41:868869.

[24] Mitzner W., Collateral ventilation, in: Crystal R.G., West J.B., et al. (Eds.), The Lung: scientific foundations, Raven Press Ltd., New York, 1991, pp. 1053-1063.

[25] Olson N.C., Brown T.T., Effects of endotoxemia on lung water and hemodynamics in conscious calves, Am. J. Vet. Res. (1985) 46:711-718.

[26] Olson N.C., Brown T.T., Dexamethasone-induced attenuation of cardiopulmonary dysfunction in endotoxemic calves, Am. J. Vet. Res. (1986) 47:2187-2192.

[27] Olson N.C., Grizzle M.K., Anderson D.L., Effects of ketanserin on pulmonary hemodynamics, lung mechanics, and gas exchange in endotoxemic pigs, Am. J. Vet. Res. (1986) 47:2193-2196.

[28] Patton D.L., Kuo S.-C., Wang S.-P., Halbert S.A., Distal tubal obstruction induced by repeated Chlamydia trachomatis salpingeal infections in pigtailed macaques, J. Infect. Dis. (1987) 155:12921299.

[29] Penttilä J.M., Anttila M., Puolakkainen M., Laurila A., Varkila K., Sarvas M., et al., Local immune responses to Chlamydia pneumoniae in the lungs of $\mathrm{BALB} / \mathrm{c}$ mice during primary infection and reinfection, Infect. Immun. (1998) 66:5113-5118. 
[30] Reinhold P., Jaeger J., Schroeder C., Evaluation of methodological and biological influences on the collection and composition of exhaled breath condensate, Biomarkers (2006) 11:118-142.

[31] Reinhold P., Deaton C., Marlin D., Potential for and limitations of exhaled breath analysis in animal models, in: Amann A., Smith D. (Eds.), Breath analysis for clinical diagnosis and therapeutic monitoring, World Scientific Publishing Co. Pte Ltd, Singapore, 2005, pp. 503-514.

[32] Reinhold P., Jaeger J., Melzer F., Sachse K., Evaluation of lung function in pigs either experimentally or naturally infected with Chlamydiaceae, Vet. Res. Commun. (2005) 29S:125-150.

[33] Reinhold P., Becher G., Rothe M., Evaluation of the measurement of leukotriene $\mathrm{B}_{4}$ concentrations in exhaled condensate as a noninvasive method for assessing mediators of inflammation in the lungs of calves, Am. J. Vet. Res. (2000) 61:742-749.

[34] Robinson N.E., Some functional consequences of species differences in lung anatomy, Adv. Vet. Sci. Comp. Med. (1982) 26:1-33.

[35] Rogers D.G., Andersen A.A., Hunsaker B.D., Lung and nasal lesions caused by a swine Chlamydial isolate in gnotobiotic pigs, J. Vet. Diagn. Invest. (1996) $8: 45-55$.

[36] Roos-Engstrand E., Wallin A., Bucht A., Pourazar J., Sandström T., Blomberg A., Increased expression of p38 MAPK in human bronchial epithelium after lipopolysaccharide exposure, Eur. Respir. J. (2005) 25:797-803.

[37] Rupp J., Droemann D., Goldmann T., Zabel P., Solbach W., Vollmer E. et al., Alveolar epithelial cells type II are major target cells for $C$. pneumoniae in chronic but not in acute respiratory infection, FEMS Immunol. Med. Microbiol. (2004) 41:197-203.

[38] Sachse K., Grossmann E., Berndt A., Schütt Ch., Henning K., Theegarten D. et al., Respiratory chlamydial infection based on experimental aerosol challenge of pigs with Chlamydia suis, Comp. Immunol. Microbiol. Infect. Dis. (2004) 27:7-23.

[39] Sävykoski T., Harju T., Paldanius M., Kuitunen H., Bloigu A., Wahlström E. et al., Chlamydia pneumoniae infection and inflammation in adults with asthma, Respiration (2004) 71:120-125.

[40] Suzuki R., Miyazaki Y., Takagi K., Torii K., Taniguchi H., Matrix metalloproteinases in the pathogenesis of asthma and COPD: implications for therapy, Treat Respir. Med. (2004) 3:17-27.

[41] Vanrompay D., Geens T., Desplanques A., Hoang T.Q., De Vos L., Van Loock M. et al., Immunoblotting, ELISA and culture evidence for Chlamydiaceae in sows on 258 Belgian farms, Vet. Microbiol. (2004) 99:59-66.

[42] Van Voorhis W.C., Barrett L.K., Cosgrove Sweeney Y.T., Kuo C.-C., Patton D.L., Repeated Chlamydia trachomatis infection of Macaca nemestrina fallopian tubes produces a Th1-like cytokine response associated with fibrosis and scarring, Infect. Immun. (1997) 65:2175-2128.

[43] Von Hertzen L., Vasankari T., Liippo K., Wahlström E., Poulakkainen M., Chlamydia pneumoniae and severity of asthma, Scand. J. Infect. Dis. (2002) 34:22-27.

[44] Waneck M., Oldner A., Rudehill A., Sollevi A., Alving K., Weitzberg E., Endothelin ${ }_{\mathrm{A}}$-receptor antagonism attenuates pulmonary hypertension in porcine endotoxin shock, Eur. Resp. J. (1999) 13:145-151. 